Orbis Tertius, vol. XXIV, $\mathrm{n}^{0}$ 29, e112, mayo-octubre 2019. ISSN 1851-7811

Universidad Nacional de La Plata

Facultad de Humanidades y Ciencias de la Educación

Centro de Estudios de Teoría y Crítica Literaria

\title{
El sinsentido como resistencia. Zombies, cyborgs y fantasmas en Literatura y otros cuentos de Martín Rejtman
}

Nonsense as Resistance. Zombies, Cyborgs and Ghosts in Literatura y otros cuentos, by Martín Rejtman

Atilio Raúl Rubino

Universidad Nacional de La Plata, Argentina

atiliorubino@yahoo.com.ar

\section{Resumen:}

Los personajes en la narrativa (literaria y cinematográfica) de Martín Rejtman han sido leidos a partir de figuras liminales entre la vida y la muerte y entre lo natural y lo artificial (zombies, fantasmas, cyborgs) en relación con la situación politico-social de la Argentina en los años noventa. Pero es posible realizar otra lectura, complementaria de la anterior, de estas figuras. A partir de conceptos como Régimen Farmacopornográfico (Preciado) o Capitalismo Mundial Integrado (Guattari), se puede repensar cómo en los relatos de Literatura y otros cuentos (2005) las prótesis tecnológicas -farmacológicas, médicas, pero también culturales-, por un lado, implican fuertes mecanismos de subjetivación pero, al mismo tiempo, propician posibilidades de agenciamiento, resistencia y fuga a los dispositivos de control.

Palabras Clave: Martín Rejtman, Prótesis tecnológicas, Capitalismo, Literatura argentina.

\section{Abstract:}

The characters in Martin Rejtman's (literary and cinematographic) narrative have been read from the basis of liminal figures between life and death and between what is natural and what is artificial (zombies, ghosts, cyborgs) in connection to the political-social situation in 1990s Argentina. However, it is possible to do a different reading of these figures which complements the previous one. From concepts such as pharmaco-pornographic regime (Preciado) or Integrated World Capitalism (Guattari), we can rethink how, in the stories in Literatura y otroscuentos (2005), the technological -pharmacological, medical, but also cultural-prostheses, on the one hand, imply strong subjectification mechanisms but, at the same time, foster possibilities for agencement, resistance to, and escape from, control devices.

KeYWORDS: Martin Rejtman, Technological prostheses, Capitalism, Argentine Literature.

\section{Prótesis tecnológicas y CAPitalismo}

Martín Rejtman es uno de los realizadores más importantes del Nuevo Cine Argentino de los años noventa. Pero antes que cineasta ha sido escritor y estas dos actividades deben ser pensadas en conjunto, como parte de un mismo proyecto creativo y un mismo estilo narrativo, tal como comenta el propio Rejtman (2006, p. 72). ${ }^{1}$ Como señala Emilio Bernini, Rejtman "procede de la literatura, pasa al cine y vuelve a la literatura, en un proceso de pasaje constante" que, a su vez, "no privilegia ninguna de las artes" $(2008$, p. 7$) .^{2}$ Sin embargo, su literatura no ha tenido la misma atención por parte de la crítica que su cine.

Se han interpretado muchas veces las narrativas de Rejtman como faltas de relieve. En ellas, una acción lleva a la otra sin que medie una relación de causa y consecuencia. Sus personajes son seres apáticos (Bernini, 2008) que actúan por inercia (Gordon, 2001), a causa del vacío que significaron las vidas para la generación de jóvenes en los años noventa, inmersas en "un mundo sin cualidades, un mundo del postrabajo, de identidades planas, sin volúmenes" (Sarlo, 2003). En este mundo sin sentido, sus personajes han sido leídos como zombies (Speranza, 2005), muertos-vivos (Setton, 2015), fantasmas (Drucaroff, 2011), robots (Gordon, 2011).Son muchos los autores que destacan que lo que impera en las narrativas de Rejtman es la lógica del mercado (Aguilar, 2010; Andermann 2015; Page, 2009; Bernini, 2008, entre otros), que muchas narraciones se centran en objetos o que los personajes son tratados como objetos (Oubiña, 2005) y que las relaciones afectivas implican transacciones. En general estas lecturas lo vinculan con la situación político- 
social argentina, fundamentalmente de la década del noventa y los primeros años del nuevo milenio. Si bien estoy de acuerdo con estas interpretaciones, me interesa pensar esta impregnación de la lógica del mercado en sus narraciones en un sentido más bien transnacional y vinculado a los usos del cuerpo y la tecnología. En este sentido, se puede pensar que se trata del poder subjetivante del capitalismo, entendido en términos de lo que Guattari llama Capitalismo Mundial Integrado, ya que al impregnar todos los órdenes de la vida, "tiende a que ninguna actividad humana, en todo el planeta, escape a su control" (Guattari, 2004, p. 57). Este capitalismo sobrecodifica todas las actividades, los flujos, el poder (Guattari, 2004, p. 75). El muertovivo, el zombie, el fantasma, el robot, también indican ese lugar liminal entre la vida y la muerte, esa zona fronteriza delineada biopolíticamente que permite la docilización y domesticación de lo humano (Sloterdijk, 2000) y que, desde esta perspectiva, se pueden considerar también como figuraciones de la resistencia. Si sus personajes son cyborgs, zombies, fantasmas, por estar docilizados en la máquina capitalista también lo son por mantenerse en un afuera interno, por ejercer cierta resistencia apática. Me interesa analizar, justamente, esta tensión entre, por un lado, dispositivos capitalísticos de control y producción de subjetividad y, por otro, las posibilidades de agenciamiento y fuga.

En este sentido, resulta fundamental pensar en el concepto de régimen farmacopornográfico de Paul B. Preciado, con el que reformula la idea de sociedades de control de Deleuze porque, según Preciado, ya no se controla a los sujetos mediante la disciplina externa sino que las tecnologías de subjetivación son internas, micro y protésicas, es decir, se convierten en cuerpo ${ }^{3}$ y para eso el capitalismo actual toma el modelo del porno y del fármaco que Preciado explica como una lógica de excitación-frustración. Se venden fantasmas, se crean necesidades cuya satisfacción es momentánea o trae nuevas necesidades. Si para Deleuze el modelo ya no era la cárcel como consideraba Foucault para la modernidad, sino la empresa, Preciado ve a las industrias pornográfica y farmacológica como modelos utópicos de toda empresa: la lógica excitación/frustración del porno y la lógica de la medicina ya no para curar enfermedades sino para concebirlas, crearlas o, en realidad, construir lo humano, delimitar lo normal. Para Preciado se trata de acciones "microprotésicas". El modelo de la empresa ya no es la producción sino la venta, pero se trata también de venta, producción y circulación de información mediática, que se hace carne, de información genética, biotecnológica, hormonal. Es por eso que el sujeto actual es el hombre postorgánico (Sibilia, 2005, p. 69), porque en él ya resulta imposible disociar la técnica de lo orgánico.

En muchas de las narraciones tanto literarias como cinematográficas de Martín Rejtman los cuerpos aparecen atravesados por discursos mayormente científicos y tecnológicos. Pero también en su materialidad son cuerpos que difuminan los límites entre lo orgánico o natural y lo artificial o tecnológico. Se trata de cuerpos tecnologizados, cuerpos protésicos, tecnocuerpos cyborgs, atravesados por discursos, por la ciencia y por la información. El propósito de este artículo es analizar en un libro de relatos en particular, Literatura y otros cuentos (2005), la relación entre prótesis tecnológicas -farmacológicas, médicas, pero también culturales -, los mecanismos de subjetivación que implican y las posibilidades de resistencia a los mismos a partir del sinsentido.

\section{FÁrMACOS MICROPROTÉSICOS Y USOS DESESTABILIZADORES}

Literatura y otros cuentos (2005) es el tercer volumen de relatos de Rejtman, antecedido por Rapado y otroscuentos (1992) y Velcro y yo (1996) y sucedido por Tres cuentos (2012). ${ }^{4}$ Está compuesto por cuatro relatos - "Alplax", "Mi yeso", "Literatura" y "Ornella"- que sitúan personajes unos años más grandes que los jóvenes de los volúmenes de cuentos anteriores, 5 que tienen hijos, como en "Mi yeso" o se casan, como en "Literatura". Los dos primeros cuentos, "Alplax" y "Mi yeso", remiten desde sus títulos a prótesis médicas y farmacológicas. El caso más claro es el de "Mi yeso". Aunque lleva por nombre una prótesis médica, el narrador-protagonista no la utiliza hasta casi el final del relato (a partir de un accidente que tiene 
con sus hijos).Cuando, al final del cuento, se lo saca siente que le falta una parte de su cuerpo:

El brazo sin yeso ahora lo siento más liviano, es como si ya no existiera la gravedad. Lo raro es que en lugar de haber ganado un brazo siento una pérdida. Algo se fue para siempre, algo irrecuperable. Toda la fuerza que desarrollé ya no tiene por dónde canalizarse, tengo más de la que necesito. Mi brazo pesa tan poco, está tan pálido, tan delgado... Es como si hubiera perdido todas las cualidades, ya no lo reconozco, dejó de ser mío, es el brazo de otro (2005, p. 43).

En el cuerpo del protagonista no hay separación entre lo natural y lo artificial. El yeso es parte de su cuerpo, es prótesis cultural tanto como su cuerpo orgánico. El cuerpo es un todo tecnovivo. Pero esta sensación de extrañamiento frente al propio cuerpo se repite en la relación que el narrador tiene con la televisión, lo que también podemos considerar una prótesis tecnológica. Como sus padres no tenían él decidió tener tres, pero las mantiene apagadas y sólo ve su reflejo en la pantalla. Frente a ésta también se siente otro, un fantasma: "Soy un fantasma adentro y afuera del aparato; no participo de ninguno de los dos mundos" (2005, p. 19). "Vuelvo a casa y enciendo el televisor para dejar de ver mi fantasma" (2005, p. 21). ${ }^{6}$ Pero no son las únicas prótesis tecnológicas. El narrador va tres veces por semana al psicoanalista (2005, p. 39). Así, el psicoanálisis forma parte de una sucesión e intercambio de tecnologías médicas, psicológicas, farmacológicas y culturales. Se trata también de una incorporación prostética. Pues, como cuenta el narrador, antes del psicoanálisis hacía yoga y aclara:

Después cambié el yoga por el psicoanálisis. Mi miedo es ahora cambiar el psicoanálisis por el autoanálisis, con este asunto del micrófono del equipo. O por la televisión. Pasé demasiado tiempo ignorándola y eso es peligroso, me dice mi psicoanalista; tanta indiferencia no puede provocar más que deseo (2005, p. 39).

Se refiere a un equipo de sonido con micrófono incorporado como adelanto tecnológico que, como le permite grabarse a sí mismo, está comenzando a reemplazar a la psicoterapia. Es interesante también tener en cuenta el uso irónico del psicoanálisis en este cuento, porque si hay algo que la crítica suele remarcar de la narrativa de Rejtman es que sus personajes carecen de psicología, de interioridad, que son más bien como autómatas (Fontana, 2017, p. 90; Sarlo, 2003, p. 141 y Oubiña, 2005, p. 210, entre otros). De hecho, el narrador parecería consiente del carácter de dispositivo tecnológico del psicoanálisis y construye un relato, cuenta cosas que le ocurrieron como si en realidad las hubiera soñado para que el psicoanalista le dé más entidad y, a su vez, omite cuestiones importantes como la muerte de su padre (2005, p. 41). Lo que se produce es un desplazamiento por distintos dispositivos farmacopornográficos como el yoga, el piscoanálisis, la televisión o el equipo de sonido con micrófono incorporado. Es interesante también contrastarlo con el personaje de Cecilia. En "Mi yeso", ella comienza una relación con su homeópata. Cuando el narrador le pregunta de dónde viene

Del homeópata -me contesta, y se le ilumina la cara y le cambia el humor-. No sabés lo bien que me hizo.

Le pregunto si ya tomó los remedios.

_ No, pero la charla sola me hizo bien. Al despedirnos le pregunté: "Doctor, ¿usted cuándo cree que voy a cambiar?”. “Tal

vez mañana mismo", me contestó (2005, p. 32).

Pero en ningún momento se dice la razón por la que Cecilia visita al homeópata. El consumo de medicación homeopática es parte del control farmacopornográfico del capitalismo. Se trata de subjetividades reguladas por los medicamentos, pues no importa qué enfermedad se tenga o si en todo caso se tiene algún padecimiento. La lógica narrativa de Rejtman nos omite las causas del accionar de los personajes y de las acciones narradas. Los narradores de Rejtman - no sólo los intradiegéticos sino también los extradiegéticos - comparten la cualidad apática de sus personajes: narran acciones sin vinculación entre sí. Es por eso que no sabemos qué padecimientos o enfermedades tienen, si tienen algunas, o las razones de los tratamientos. Paula Sibilia (2005) explica cómo la investigación biomédica ya no se encarga de la cura de enfermedades sino de la prevención de los riesgos. No todos tenemos enfermedades pero sí, en tanto humanos, tenemos 
errores en términos de probabilidad, en ese sentido todos somos objeto de este tipo de biopolíticas: "las estrategias de biopoder que apuntan a la prevención de riesgos involucran a todos los sujetos a lo largo de toda la vida, con su imperativo de la salud y su amplio menú de medidas preventivas: alimentación, deportes, psicofármacos, vitaminas, terapias, etcétera." (Sibilia, 2005, pp. 248-249). Sin embargo, como un acto de rebeldía (quizá inconsciente) Cecilia toma todo el frasco con los remedios homeopáticos juntos (2005, p. 33). Y lo hace sin que se explicite ninguna razón. En este sentido es importante notar la diferencia con otros relatos del autor. Por ejemplo, el personaje de Cecilia en la película Los guantes mágicos antes de conocer a Susana se caracterizaba por el tedio, el vacío, el aburrimiento. Es Susana la que le pone un nombre médico a su comportamiento: depresión. Y con ello, posibles soluciones, primero un viaje a Brasil, porque Susana trabaja en turismo, luego medicamentos antidepresivos. Luego vendrá un nuevo diagnóstico, la adicción a los medicamentos y al alcohol y el aumento de peso, la solución será nuevamente un viaje, luego caminatas y yoga. La enfermedad como signo nuevo trae una medicación que, lejos de curarla le genera una adicción que hay que combatir con terapias new age como el yoga y los viajes al spa. Así, siguiendo a Sibilia, cualquier malestar o padecimiento se convierte en un error en el código fisiológico, un error que debe ser corregido mediante medicamentos y psicofármacos. Pero ese error o desvío se entiende siempre respecto a un modelo de normalidad. El estado de ánimo de Cecilia, así, es decodificado como un desvío de la norma, una enfermedad, que debe ser corregida con psicofármacos. Luego el desvío será la adicción, luego el aumento de peso. Así, se lleva a cabo la biopolítica a nivel microprotésico. Todos los cuerpos son regulados y autoregulados desde dentro.

Como la Cecilia de Los guantes mágicos, la de "Mi yeso" no tenía ningún padecimiento. Pero ante esto la actitud aparentemente sin sentido de tomar todo el frasco de remedios constituye un acto de resistencia a la normalización tecnobiopolítica, un uso desviado de las prótesis tecnológicas, como el uso del televisor apagado o del grabador de sonido en reemplazo del psicoanálisis. Si en Los guantes mágicos se corregía el desvío inherente al ser humano mediante la medicación y otras prótesis, en "Mi yeso" podemos pensar el camino inverso: de la corrección de la falla como probabilidad-la homeopatía o el psicoanálisis-al desvío deliberado. La corrección constante del régimen farmacopornográfico es la que permite el desvío, que se registra como un sinsentido. En el fondo, si Cecilia no tiene razón alguna para tomar todo el frasco de medicamentos tampoco la tenía para administrarse las dosis indicadas.

Una prótesis farmacológica es la que también da título al primer cuento del volumen, "Alplax", que, justamente, comienza con la referencia al consumo de medicamentos sin sentido (aparente) o por lo menos sin que obedezca a la cura o tratamiento de una enfermedad o dolencia -a diferencia de lo que ocurría con el personaje de Cecilia en Los guantes mágicos. Todo el cuento está atravesado por el consumo de alplax por parte de la protagonista, pero sin que medie una receta médica, un diagnóstico, o un padecimiento que pueda explicar ese comportamiento. Paula Sibilia se refiere al auge de los psicofármacos que reemplazan en parte al psicoanálisis: "Una serie de drogas surgidas en las últimas décadas, con gran éxito publicitario, mercadotécnico, terapéutico y subjetivante en todo el mundo, constituyen buenos ejemplos de esa transición: Prozac, Lexotanil, Vallum, Citalopran y Ritalina forman parte de ese grupo." (Sibilia, 2005, p. 235). Se trata de prótesis farmacológicas, internas, que delimitan y administran las subjetividades y las vidas:

El éxito de la tecnociencia contemporánea es transformar nuestra depresión en Prozac, nuestra masculinidad en testosterona, nuestra erección en Viagra, nuestra fertilidad/esterilidad en píldora, nuestro sida en triterapia. Sin que sea posible saber quién viene antes, si la depresión o el Prozac, si el Viagra o la erección, si la testosterona o la masculinidad, si la triterapia o el sida. Esta producción en auto-feedback es la propia del poder farmacopornográfico (Preciado, 2014, pp. 36-37).

En "Alplax" hay una escena que nos remite a la película de Almodóvar Mujeres al borde de un ataque de nervios (1988). En ella Ana, la protagonista, hace licuados para tomar con sus amigas y le pone alplax: "Con el martillo de aplastar milanesas muele seis alplax y mete el polvillo en la licuadora junto con la leche y las bananas" (2005, p. 17). Sólo que en la película de Almodóvar se trataba de somníferos y éstos tenían una razón de ser, dormir a quienes lo tomaran. En "Alplax", no hay ninguna razón para el consumo de este medicamento. 
Respecto de este cuento, María Fernanda González (2010) afirma que el uso de ansiolíticos funciona como una salida rápida ante lo inconmensurable de la experiencia. De esta forma, González le da un sentido a la ingesta de ansiolíticos, aunque en realidad en el cuento no lo tiene o, al menos, no se lo explicita. Como afirma Aguilar, "la falta de relieve, que es una de las marcas más personales del cine de Rejtman, lleva a los espectadores y a los críticos a apropiarse de un momento del film y leerlo como clave, en un gesto que siempre resultará violento" (2010, p. 92, n 58 ). Lo que yo leo, en cambio, es justamente ese sin sentido, esa ausencia de razón o causa, como un acto de resistencia abúlico. Lo que me interesa es que tanto Cecilia en "Mi yeso" como Ana en "Alplax" consumen los medicamentos porque sí, a diferencia del personaje de Cecilia en Los guantes mágicos.

\section{UNA SÍNTESIS DE CAPITALISMO Y SOCIALISMO}

Quiero retomar un detalle de "Mi yeso" que no mencioné antes. Se trata de la relación de Ezequiel (el hermano del narrador) con Lipo, un supuesto amigo. Esta relación aparece en el trasfondo de la del narrador con Ezequiel. Mucho no se dice pero podríamos considerarla sexo-afectiva, como ocurría con otros textos en la obra literaria y cinematográfica de Rejtman. ${ }^{7}$ Ezequiel y Lipo viven juntos desde hace tres meses, luego se pelean y Ezequiel vuelve a casa del narrador, hasta que se reconcilian y vuelve con Lipo. Así relata el narrador el momento en el que se conocen:

Un día Ezequiel me pidió que le deje el departamento para él solo porque tenía una cita con un ceroseiscientos. Los cerosescientos son esos servicios en los que se conoce gente por teléfono. Esa noche dormí en casa de un amigo y cuando volví a las nueve de la mañana, Lipo y Ezequiel estaban instalados en el living con las persianas bajas y las luces encendidas, completamente despiertos. Sobre mi mesita ratona había tres botellas de whisky y dos de tequila (2005, p. 22).

A pesar de que el narrador los llama amigos (2005, p. 22), y de que a veces salen con amigas que él supone que "son también ceroseiscientos" (2005, p. 23), parece tratarse de una relación sexo-afectiva. De hecho, Ezequiel se va a vivir con Lipo hasta que éste lo echa porque "hizo una fiesta y no le avisó (...). Lo encontró a Ezequiel con tres chicas en su cuarto" (2005, p. 31). Pero luego, "hacen las paces" (2005: 35) y vuelven a vivir juntos. En los personajes de Rejtman parecería haber una sexualidad fluida. La apatía que caracteriza su accionar (Bernini, 2008, p. 36) también se puede pensar en sus relaciones sexo-afectivas y en su identidad sexual, ya que nunca se marca una homo o heterosexualidad fija. Esta sexualidad no heterosexual pasa como desapercibida tanto para el narrador como para el lector, pues la distinción binaria homo/hetero parecería no funcionar. Esta trama, si bien no constituye una clara relación homosexual, permite hacer una lectura que entienda las sexualidades de estos personajes en continuo movimiento. La errancia y la fuga típica de los personajes de Rejtman parecen también definir a la sexualidad en estos relatos. La fluidez de la sexualidad que escapa a la axiomatización identitaria también funciona como una resistencia a un sistema, el capitalismo, que otorga sentido a todos los órdenes de la vida, como puede verse también de forma irónica en el cuento "Ornella".

Los protagonistas de "Ornella" emprenden el proyecto de un TodoShow, "un multiespacio veinticuatro horas para todo tipo de shows y eventos, desde temprano en la mañana hasta tarde en la madrugada, y para todas las edades: desayuno-guardería, almuerzo-jazz, animación infantil, cena-tango o magia adulta, medianoche erótica y acto sexual en vivo" (2005, pp. 84-5), como si el mercado o el capitalismo (condensado en la alegoría del TodoShow) asimilara todas las posibles identidades, todas las posibles fugas, como ocurre posteriormente con la venta de los derechos a una multinacional con sede en Australia. Para Rodrigo Caresani, este cuento "podría leerse como una indagación estética sobre la nueva experiencia del espacio en la trama caótica y proliferante de la urbe actual” (2012, p. 123). Pero habría que pensar que el espacio aquí es lo que en los términos de Paul B. Preciado (2014) podemos llamar farmacopornomegalópolis. Siguiendo a Hardt y Negri Preciado concibe la estructura geopolítica actual como "una única ciudad 
difusa interconectada con centros de intensidad, circuitos de circulación de capital, cuerpos e información, zonas de producción y de deyección de detritus materiales y semióticos" (Preciado, 2014, p. 269). La farmacopornomegalópolis es, se podría decir, el centro de irradiación del Capitalismo Mundial Integrado. Por eso, cuando se emprende el proyecto "TodoShow” en Australia, en carpas instaladas durante siete días, el resultado es aún más significativo:

El lugar se llena de todo tipo de personajes: queers, skinheads, hippies, tatuados, granolas, ravers, bodybuilders, ecologistas, gente con piercings, punks, nuevos darks, anarquistas, Chicago boys, fanáticos de Mad Max, militantes antiglobalización, mods, new agers, beatniks, nerds, neonazis, skaters (2005, p. 112).

Lo que ocurre con la venta de "TodoShow" a Australia es un evento en carpas con una amplia y heterogénea oferta destinada a todas las posibles identidades. Todas subsumidas por el mercado. Por eso, TodoShow es "la síntesis perfecta entre socialismo y capitalismo" (2005, p. 99) que "convoca a gente de todos los credos y tendencias sexuales" (2005, p. 97). Y por eso la Iglesia lo ve como una amenaza, pero no por una cuestión moral o ideológica, sino porque constituye una competencia en el mercado por otorgar sentido a las vidas y a la realidad. La Iglesia y la religión también son un bien de mercado y forman parte de esa red de conexiones planetaria que es la farmacopornomegalópolis. De esta forma, la apatía de algunos de los personajes de Rejtman, el rechazo a que se le otorgue un significado a sus vidas, puede funcionar como fugas a este sistema.

El cuento en el que esto se puede ver más claramente es el que le da título al volumen, "Literatura". Este relato sigue el trayecto de Andrés, su narrador. Aunque -como es característico en Rejtmam- no hay una clara progresión causal en la historia, se pueden leer dos líneas narrativas. Por un lado, la relación de Andrés con la escritura de literatura, algo que aparentemente sí lo motiva pero que queda más solapado. Y, por otro lado, la relación con Mónica (conocerse, ponerse en pareja y casarse) y con su padre (a quien visita en Caracas y luego viaja para su casamiento). El cuento pone en funcionamiento un sistema de extrañamiento de la normalidad de la familia. Para Aguilar el cine argentino de la generación de Rejtman plantea dos direcciones en relación con la idea de familia y la desintegración de ese mundo. Por un lado, el sedentarismo implica la permanencia en el orden familiar y "un proceso de disgregación y una inmovilidad, una parálisis y un letargo" que genera "la descomposición de los hogares" (2010, p. 41). El nomadismo, por otro lado, significa "la ausencia de hogar, la falta de lazos de pertenencia poderosos (restrictivos o normativos) y una movilidad permanente e impredecible" (2010, p. 41). Aguilar ubica tanto el cine como la literatura de Rejtman en esta segunda tendencia. En "Literatura" se puede ver claramente el distanciamiento irónico respecto a la matriz familiar. Así, cuando Andrés se casa se siente durante toda la fiesta "como si fuera el casamiento de otro" (2005, p. 62).Ya antes de este hecho, cuando viaja a Caracas a ver a su padre que tuvo un accidente y provechó la internación para hacerse un lifting, no lo reconoce. Este extrañamiento respecto de la pertenencia familiar se vuelve más irónico en el final del cuento, ya que todos se reúnen en la casa de la madre de Andrés, que es la misma casa familiar en la que éste se crió, sólo que su madre compró tiempo después del divorcio sin decirle a su nueva pareja que ya había vivido ahí. La idea de familia como un sentido que ya queda obsoleto se vuelve en esta parte más irónica: "Me siento extraño: estoy en la casa en la que nací, rodeado de mi familia más cercana" (2005, p. 64), ya que, como narra Andrés, "después de todo en esta misma casa él, mi madre y yo formamos una vez una familia” (2005, p. 64). Lo irónico es que al final, cuando está junto a su padre y su madre en lo que era la casa familiar en la que vivieron juntos, todo le sigue resultando extraño: "y no puedo dejar de preguntarme si la edad que aparenta hoy, después del estiramiento, no coincidirá con la que tenía catorce años atrás, cuando se fue del país" (2005, p. 65). Como si el cuento traicionara los intentos por buscar un sentido a las identidades en el seno del núcleo familiar. También la familia, aquí, es una prótesis, una tecnología que dociliza los cuerpos y subsume las identidades a las reglas del mercado, a la lógica del Capitalismo que es lo único que dota de sentido tanto a las personas como a las cosas.

Andrés se casa con Mónica y planean vivir juntos en Bariloche, la prótesis familiar sigue ejerciendo su poder a pesar de la forma extrañada y apática con que la ve. Sin embargo, su verdadera resistencia a los 
mecanismos docilizadores es la literatura. Justamente porque su relación con ella es, también, desviada. Para Andrés escribir literatura es lo único significativo en su vida. Sin embargo Mónica le hace preguntas que lo enfrentan a la valoración del mercado, que insertan ese interés dentro de la lógica mayor del capitalismo que le da sentido:

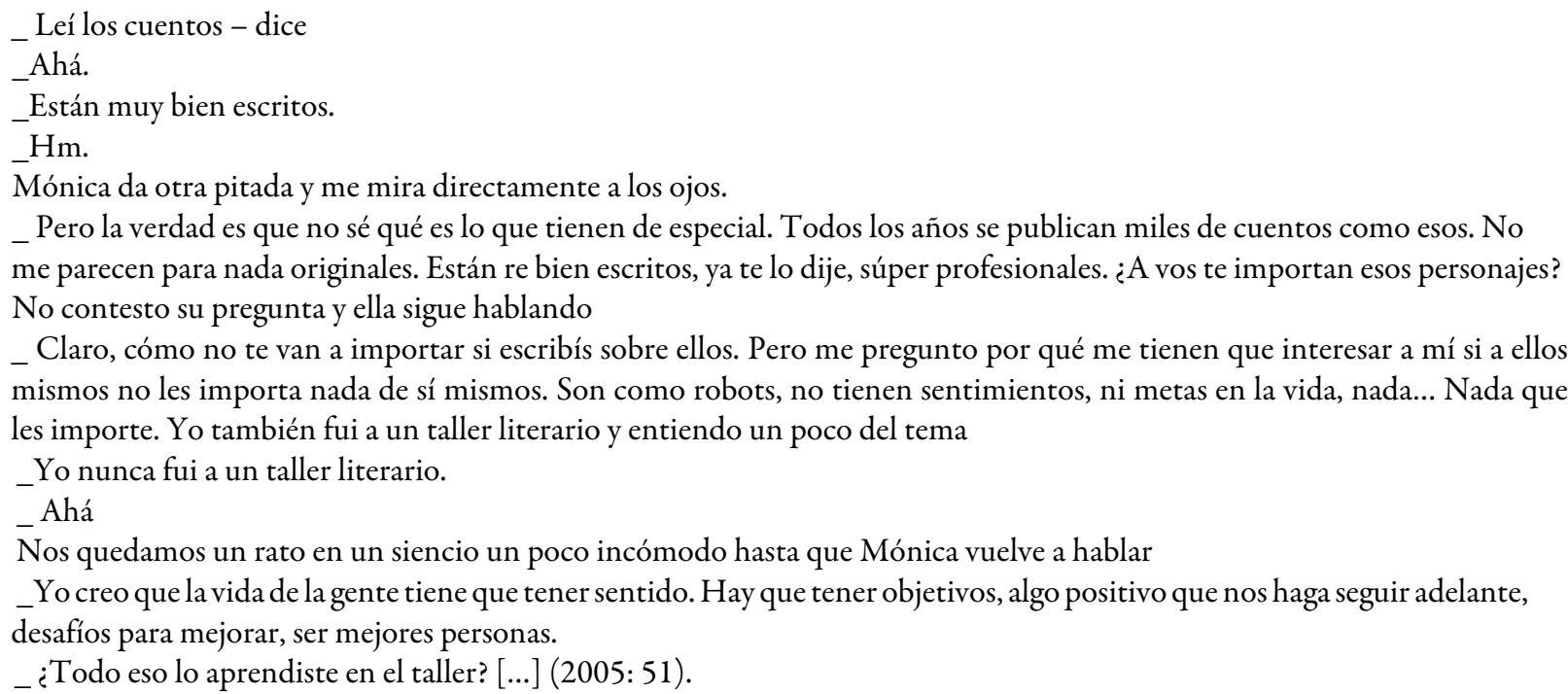

En este intercambio entre Mónica y Andrés se pone de manifiesto el imperativo de que la vida o las acciones tengan un sentido "donde tener sentido y entrar en la vida no son otra cosa que asumir cierta posición determinada en el juego de roles e identidades sociales reconocidas" (Sánchez, 2014, p. 220). La literatura, en sí, no tiene sentido desde el punto de vista del valor de cambio. Desde el principio, el narrador de "Literatura" asegura que eso es lo único que le importa y el cuento también se cierra con el narrador preocupado por ese aspecto: "Tengo miedo de que vean mi relación con la literatura con desprecio, como si se tratara de algo bastardo, de un episodio intrascendente en mi vida; que puedan ver que para mí la literatura es un accidente que podría no haber ocurrido" (2005, pp. 65-66). Lo que sí parece intrascendente para el narrador son sus proyectos de vida, el matrimonio, la mudanza a Bariloche y los planes laborales y de familia allí, es decir, todo lo vinculado con "objetivos [...] desafíos para mejorar, ser mejores personas", en palabras de Mónica.

En ese sentido es importante revisar también el inicio del cuento. En él, Andrés está bailando en una disco y se deja llevar por el ritmo en una especie de estado de trance:

Paro un segundo de bailar y me doy cuenta de que estoy agitado, así que decido salir de la pista y tomarme un descanso. Ya hace casi tres horas que bailo sin parar (...). Sin querer empiezo a seguir el ritmo de la música con el pie; pego golpes cada vez más fuertes contra el piso de madera y puedo escuchar el ruido de la suela de mi zapato junto con la música. De a poco empiezo a mover rítmicamente la cabeza también, a toda velocidad, hasta que los movimientos se convierten en convulsiones. Muevo todo el cuerpo como si estuviera en trance con tanta violencia que volteo el vaso de gin tonic que dejé apoyado sobre la mesa al lado del sillón $(2005$, p. 45)

La música y el baile como un trance es una constante en Rejtman. Aguilar llama la atención sobre el tema que baila Alejandro en el final de Los guantes mágicos, "Vanishing point" de New Order (Aguilar, 2010, p. 110) y es que el baile y la música, justamente, pueden ser interpretados como líneas de fuga a la lógica capitalista, porque, como observa Depetris Chauvin (2012, p. 229), los que bailan son cuerpos que no producen y tampoco significan. Bailar solo es un sinsentido, un trance, una experiencia claramente desubjetivante, en la que "the individual who dance disappears in sound" (2012: 226). Pero bailar acompañado, con alguien, es completamente distinto. Se trata de un acto comunitario y, en algún sentido, también de comunicación. El cuerpo que baila con alguien sí produce un significado en la comunicación con ese otro: 
En medio de la pista bailo un rato solo junto con Hugo y, cuando me doy vuelta, enfrentado a Mónica. Sigo moviéndome, la veo a ella también moverse, y me pregunto si estaremos bailando juntos. Cada tanto la miro para saber cuál es realmente la situación, pero ella mira todo el tiempo para otro lado (2005, p. 49)

El baile no produce un valor de mercado, es gasto, como la literatura para Andrés. Pero si ésta entra en el circuito de la publicación, ahí sí adquiere un sentido mayor otorgado por la circulación mercantil, por el capitalismo. ${ }^{8}$ El sonido en este sentido-la música, el baile-desterritorializan el significado. En la narrativa de Rejtman no se trata sólo del rechazo de la retórica cinematográfica de los ochenta, tal como ha sido analizado a menudo (Bernini, 2008. P. 11; Rozenmacher, 2012, p. 242; Andermann, 2015, p. 50; Prysthon, 2013, p. 96 y Campero, 2014, p. 22, entre otros), sino también de un escape a las formas establecidas del habla, de la comunicación, como una forma de eludir la tiranía del lenguaje y escapar a la lógica del mercado (Depetris Chauvin 2012: 230). Se podría decir que en un mundo hipersemiotizado la literatura, la música y la imagen pueden ser no significantes.

\title{
EL SINSENTIDO COMO FUGA
}

\section{Graciela Speranza denomina "realismo idiota" al estilo de Rejtman, porque}

\begin{abstract}
No hay significación oculta, promesa de un sentido lejano, sino apenas una significación inmediata, muda y anodina. Los personajes se entrecruzan como zombis en la confusión de caminos pero los narradores no los aventajan en la comprensión del mundo. [...] Si hay algo, en todo caso, en el fondo inasible de estos relatos, es la sospecha [...] de que también la realidad es idiota (Speranza, 2005, p.10).
\end{abstract}

A pesar de esto, para Speranza, "dispersos aquí y allá, sin premeditación y sin énfasis, brillan leves destellos poéticos en los que todavía se reconocen las condensaciones sensibles de la figuración realista (...)” (Speranza, 2005, p. 9). Sin embargo, habría que distinguir aquí la idiotez en el accionar de los personajes y la de la realidad. Pues esa realidad idiota a la que hace mención Speranza no es más que el capitalismo diseñando todos nuestros pasos, nuestros deseos, nuestras motivaciones a tal punto que la "idiotez" de los personajes puede considerarse también como un punto de fuga a esa lógica de mercado que dota de significación los cuerpos en la narrativa de Rejtman. En el accionar de los personajes la idiotez y el sinsentido que los hace ver como zombies o fantasmas es al mismo tiempo el disciplinamiento y la subjetivación capitalista y una posibilidad de resistencia a esa sujeción. Si la realidad es idiota, esa idiotez es el Capitalismo Mundial Integrado (Guattari, 2004) o la Farmacopornomegalópolis (Preciado, 2014) en donde a veces eso que puede leerse como idiotez (recordemos el significado etimológico de ídıc/idios: único, particular, personal) o "destello poético" no es más que una asombrosa lucidez: el sinsentido (o su contrario, la sobrecodificación) de la vida en la maquinaria farmacopornográfica. Como comenta Preciado, "nuestra presencia ante nosotros mismos como especie puede calificarse hoy de prostético-comatosa. Hemos cerrado los ojos, pero seguimos viendo a través de un conjunto de tecnologías, de implantes políticos a los que llamamos vida, cultura, civilización. Sin embargo, solo desde y a través de este dispositivo biotecnológico, es posible osar la revolución” (2014, p. 270). Así, si hay gestos de rebelión en los personajes, éstos son micro (microrevoluciones, gestos micropolíticos, moleculares, desobediencias microprotésicas) y ya no los grandes discursos revolucionarios de la generación anterior.

En este sentido se pueden pensar tanto la ingesta de alplaxpor parte de Ana como la de los remedios homeopáticos por parte de Cecilia e, incluso, la literatura para Andrés -y, acaso, las relaciones sexoafectivas innominadas como las de Ezequiel y Lipo. Se trata de tecnologías capitalistas de subjetivación -medicamentos farmacológicos, homeopáticos, literatura, familia, identidad sexual- pero usadas como resistencia y agenciamiento a partir del sinsentido, de la fuga de la racionalidad, del desvío, del mal uso deliberado.Como afirma Elsa Drucaroff, Rejtman encuentra gestos de rebeldía e inconformismo en la banalidad y el capricho de sus personajes (2011, p. 125). El cuerpo en los cuentos de Rejtman está fuertemente constituido por la técnica, farmacológica, médica, pornográfica, etc. Son tecnologías fuertemente 
subjetivantes que controlan la población y al individuo como modernísimas biopolíticasmicroprotésicas. Pero también ahí radica su fuerte valor transgresor y de rebeldía. En Rejtman "la mercancía es el medio en el que se vive y aquello que hay que recorrer y atravesar para llegar a la experiencia” (Aguilar, 2010, p. 74). $\mathrm{Si}$, para Andrés, la literatura es prótesis, se trata entonces de un uso subversivo de la prótesis, cooptado por el capitalismo mundial y la lógica del mercado que no sólo hace que un escritor sea equivalente a un escritor publicado sino también que persona sea equivalente a -o adquiera sentido sólo en el marco de - familia. Lo no-persona son los fantasmas que merodean las narrativas -fílmicas y literarias- de Rejtman en los intersticios de lo no dicho.

Por eso también Ana en "Alplax" toma el medicamento como una forma de resistencia abúlica al sistema farmacopornográfico. Esa dimensión del sinsentido no necesariamente es la falta de contexto, de significados, de valores o de ideología-como se ha leído en la narrativa de Rejtman, sobre todo a partir del artículo de Sarlo (2003)-, sino que también pueden constituir mecanismos de resistencia a los sentidos que son la producción capitalista y farmacopornográfica de subjetividad. En esta línea, podríamos preguntarnos si en un mundo en donde todos los órdenes de la vida, quizá, están delineados por el capitalismo, la apatía, el sinsentido y la improductividad no pueden ser otras formas de habitarlo, que escapen -o bien resistan-a la lógica capitalística y la hipersemiotización.

\section{REFERENCIAS}

Aguilar, G. (2010). Otros mundos. Un ensayo sobre el nuevo cine argentino, Buenos Aires, Argentina: Santiago Arcos. Andermann, J. (2015). Nuevo cine argentino, CABA, Argentina: Paido\#s

Bernini, E. (2008). Estudio Crítico sobre Silvia Prieto. Entrevista a Martín Rejtman, Buenos Aires, Argentina: Picnic.

Campero, A. (2014). Nuevo cine argentino. De Rapado a Historias extraordinarias, Los Polvorines, Argentina: Universidad Nacional de General Sarmiento y CABA, Biblioteca Nacional.

Caresani, R. (2012). “Nuevos realismos en la escena literaria argentina: Fabián Casas versus Martín Rejtman”, en Texturas, UNL, no 12 (12), pp. 111-128.

Depetris Chauvin, I. (2012). "Voice, Music and the Experience of the Neutral in Martín Rejtman's Fictions", en Hispanic Issues On Line, no. 9, pp. 214-236.

Drucaroff, E. (2011). Los prisioneros de la torre: politica, relatos y jóvenes en la postdictadura, Buenos Aires, Argentina: Emecé.

Fontana, P. (2018). “Últimas imágenes del nuevo cine argentino: Martín Rejtman y Lisandro Alonso", en Emilio Bernini (ed.), Después del nuevo cine. Diez miradas en torno al cine argentino contemporáneo, Buenos Aires, Argentina: EUFyL, pp. 87-98.

González, M. F. (2010). "Martín Rejtman: La representación de la futilidad de la experiencia cotidiana en la década del 90”, en VI Jornadas de Sociología de la UNLP, La Plata, FaHCE-UNLP.

Gordon, R. (2011). “Cine y literatura en Martín Rejtman: Estética de la inercia y contemporaneidad”, en Revista De Critica Literaria Latinoamericana, 37(73), pp. 289-305.

Guattari, F. (2004). Plan sobre el planeta. Capitalismo mundial integrado y revoluciones moleculares, Madrid, España: Traficantes de Suen\#os.

Haraway, D. (1995). Ciencia, Cyborgs y mujeres. La reinvención de la naturaleza, Madrid, España: Cátedra.

Oubiña, D. (2005). "Martín Rejtman: el cine menguante”, en Martín Rejtman, Rapado, Silvia Prieto, Los Guantes Mágicos, Doli vuelve a casa, Buenos Aires, Argentina: Colección Cine Malba

Page, J. (2009).Crisis and capitalism in contemporary Argentine cinema, Duke University Press, Reino Unido: Durham. Preciado, P. B. (2014). Testo yonqui: sexo, drogas y biopolítica, Buenos Aires, Argentina: Paidós. 
Prysthon, A. (2013). "La sensibilidad de lo banal en el cine contemporáneo", en Jens Andermann y Álvaro Fernández Bravo (comps.), La escena y la pantalla: cine contemporáneo y el retorno de lo real, Buenos Aires, Argentina: Colihue, pp 93-109.

Rejtman, M. (2006). “Poética”, en Eduardo Becerra (ed.), El arquero inmo\#vil: nuevaspoe\#ticas sobre el cuento, Madrid, España: Pa\# ginas de Espuma, pp. 71-3.

Rejtman, M. (2005). Literatura y otros cuentos, Buenos Aires, Argentina: Interzona.

Rozenmacher, L. (2012). “Combustible mezcla. Relación y acontecimiento a partir de Rapado de Martín Rejtman”, en Gustavo Aprea (comp.), Filmar la memoria. Los documentales audiovisuales y la re-construcción del pasado, Los Polvorines, Argentina: Universidad Nacional de General Sarmiento.

Rubino, A. (2015). "Sexualidades en fuga. Cuerpo e identidad en la literatura y el cine de Martín Rejtman”, en Saga. Revista de Letras, $\mathrm{n}^{\circ} 3$, (primer semestre de 2015).

Sánchez, S. (2014). "Repensar la cultura: Williams”, en Miriam Chiani (Dir.), Cuadernos de teoría, La Plata, Argentina: Al margen, pp. 195-225.

Sarlo, B. (2003). "Plano, repetición: Sobreviviendo en la ciudad nueva”, en Alejandra Birgin y Javier Trímboli (eds.), Imágenes de los noventa, Buenos Aires, Argentina: Libros del Zorzal, pp. 125-149.

Setton, R. (2015). “El regreso de los muertos vivos (Dos disparos de Martín Rejtman)”, en Kilómetro 111. Ensayos sobre cine, $\mathrm{n}^{\circ} 13$.

Sibilia, P. (2005). El hombre postorgánico. Cuerpo, subjetividad y tecnologías digitales, Buenos Aires, Argentina: Fondo de Cultura Económica.

Sloterdijk, P. (2000). Normas para un parque humano. Una respuesta a la Carta sobre el humanismo de Heidegger, Madrid: Siruela.

Speranza, G. (2005). "Por un realismo idiota”, en Boletin/12 del Centro de Estudios de Teoría y Crítica Literaria, pp. $1-11$.

\section{Notas}

1 En el breve texto en el que Rejtman da cuenta de su poética, afirma "Para mí el cine y la literatura estuvieron juntos desde el principio. Empecé a escribir literatura cuando todavía estudiaba cine en la universidad. Escribo mis propios guiones y el mundo del que hablo en las películas es el mismo mundo de los cuentos" (2006, p. 72).

2 Su primer largometraje, Rapado, resultó precursor de lo que después se constituyó como el nuevo cine argentino de los noventa (Oubiña, 2005, p. 5). Pero antes de la película mencionada existió el volumen de cuentos homónimo. Y justamente por eso se puede decir que la literatura es "uno de los elementos que están en el inicio del nuevo cine" (Bernini, 2008, p. 8).

3 Tomando el antecedente del Manifiesto cyborg de Donna Haraway (1995), Preciado considera al cuerpo como prostético. En el Manifiesto contrasexual le dará una importancia al dildo para deconstruir la idea del falo como el centro del placer heterosexual. En Testo Yonqui se centrará en las prótesis a nivel más micro, prótesis tecnológicas y farmacológicas, "ni cuerpo organismo ni máquina: tecnocuerpo", ya que "el cuerpo individual funciona como una extensión de las tecnologías globales de comunicación (...).El cuerpo del siglo XXI es una plataforma tecnoviva, el resultado de una implosión irreversible de sujeto y objeto, de lo natural y lo artificial” (Preciado, 2014, p. 42).

4 Otros relatos cortos han sido editados en compilaciones, así como algunos de sus guiones, Entrenamiento elemental para actores (2014, en coautoría con Federico León) y Rapado. Silvia Prieto. Los guantes mágicos (2012).

5 Lo mismo se ha destacado en su cine en el paso de Rapado (1992) a Silvia Prieto (1999) y Los guantes mágicos (2003).

6 Esta sensación de extrañamiento frente a sí mismo se repite en otras partes: "Me doy cuenta de que el que ven no soy yo" (2005, p. 25); “...Veo otra vez mi fantasma, ahora en el vidrio de la ventana” (2005, p. 24).

7 Esto puede leerse en relación con algunos otros textos del autor, como la película Rapado (1992) -respecto a la que críticos como Oubiña (2005, p. 21) y Aguilar (2010, p. 55) mencionan la posibilidad de una lectura homosexual- y algunos relatos del volumen Rapado y otros cuentos, como el cuento "Algunas cosas importantes para mi generación". Sobre estos textos cf. Rubino (2015).

8 De hecho son Mónica y su padre los que insertan la literatura de Andrés en la lógica del mercado. El padre de Mónica le paga la edición de su libro porque "prefiere que su hija esté de novia con un escritor publicado antes que con uno inédito" (2005, p. 53). 